\title{
Correlation between Fatigue and Ability to Perform Activities of Daily Living in Myasthenia Gravis Patients
}

\author{
Adesti Permanasari ${ }^{1 *} \mathbb{D}$, Damayanti Tinduh $^{1} \mathbb{D}$, Indrayuni Lukitra Wardhani ${ }^{1} \mathbb{D}$, Imam Subadi ${ }^{1}$, Paulus Sugianto ${ }^{1}$, \\ Yudith Dian Prawitri ${ }^{2}$ D \\ ${ }^{1}$ Department of Physical Medicine and Rehabilitation, Faculty of Medicine, University of Airlangga, Dr. Soetomo General \\ Academic Hospital, Surabaya, Indonesia; ${ }^{2}$ Department of Neurology, Faculty of Medicine, University of Airlangga, Dr. Soetomo \\ General Academic Hospital, Surabaya, Indonesia
}

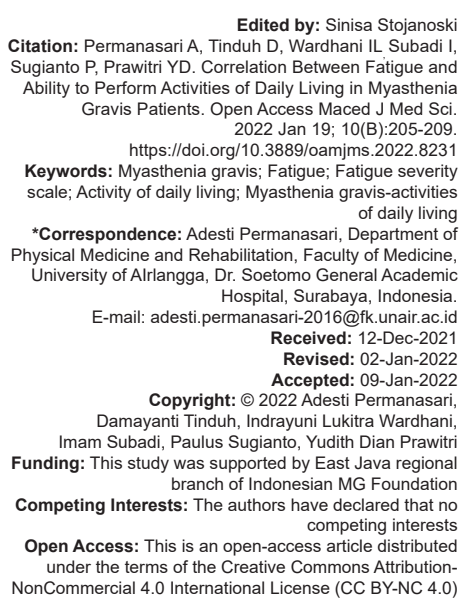
Edited by: Sinisa Stojanoski Citation: Permanasari A, Tinduh D, Wardhani IL Subadi I Ability to Perform Activities of Daily Living in Myastheni Gravis Patients. Open Access Maced J Med Sci. 2022 Jan 19; 10(B):205-209 2022 Jan 19; 10(B):205-209
https://doi.org/10.3889/oamjms.2022.823 Keywords: Myasthenia gravis; Fatigue; Fatigue severity scale; Activity of daily living; Myasthenia gravis-activities of daily living "Correspondence: Adesti Permanasari, Department of Physical Medicine and Rehabilitation, Faculty of Medicine, ( Hospital, Surabaya, Indonesia. E-mail: adesti.permanasari-2016@fk.unair.ac.I Revised: 02-Jan-2022 Accepted: 09-Jan-2022 Copyright: ๑ 2022 Adesti Permanasa Damayanti Tinduh, Indrayuni Lukitra Wardhani Imam Subadi, Paulus Sugianto, Yudith Dian Prawitr Funding: This study was supported by East Java regional branch of Indonesian MG Foundation
Competing Interests: The authors have Competing Interests: The authors have declared that no Open Access: This is an open-access article distributed under the terms of the Creative Commons AttributionNonCommercial 4.0 International License (CC BY-NC 4.0)

\begin{abstract}
BACKGROUND: Myasthenia Gravis (MG) is an autoimmune disease of the neuromuscular junction that has autoantibodies that can be found in most cases. Fatigue and skeletal muscle weakness are the pathognomonic symptoms of MG and can be severely disabling, interfering with a patient's ability to pursue activities of daily living, limiting their work, family, and social lives.

AIM: This study aimed to analyze the correlation between fatigue and the ability to perform activity of daily living (ADL) among patients with MG.

METHOD: Fatigue severity scale (FSS) was used to measure the fatigue and MG-ADL scale was used to evaluate the patient's ability to perform ADL. Rank-Spearman test was used to assess the correlation between fatigue and patient's ability to perform daily activities.

RESULTS: Thirty-one patients (nine males and 22 females) with MG were included and classified into three subgroups of fatigue: Non-fatigue (FSS $<4)$, borderline $(4<F S S<5)$, and fatigue (FSS $>5)$. There was a significant correlation between fatigue and the patient's ability to perform ADL ( $p=0.005 ; p=0.488)$ with $\mathrm{Cl} 95 \%$.
\end{abstract}

CONCLUSION: Fatigue in patients with MG correlates with the ability to perform ADL.

\section{Background}

Myasthenia gravis (MG) is one of the most common autoimmune diseases of the neuromuscular junction. Globally, the incidence is more than $10 / 1,000,000$ people with the typical symptoms of fatigue and skeletal muscle weakness that fluctuate, worsening with activity, and improving after resting [1], [2], [3]. Current evidence suggests that fatigue has a greater impact than muscle weakness in patients with MG [4], [5], [6]. Fatigue can be very disturbing, hampering and affecting the patient's ability to perform daily activities in their family, social, and work environments [7].

The primary fatigue that occurs in $M G$ is physical fatigue due to muscle weakness and increased susceptibility to fatigue. About $80 \%$ of patients complain of fatigue [5], [7], [8]. The systematic review conducted by Ruiter et al. revealed that fatigue is the most common symptom that complained by the patients with poor quality of life and is an obstacle in doing daily activities [9], therefore need to be addressed. The prevalence of fatigue in MG patients increases along with severity, from $32 \%$ of patients with pharmacological remission to $72 \%$ of patients with generalized weakness. Chronic fatigue, defined as fatigue lasting 6 months, occurs in $21-72 \%$ of patients [9]. Hoffmann et al. [5] found that daily activity of patients assessed using the MG-Activities of Daily Living (MG-ADL) score was significantly higher in patients with the lower fatigue $(p<0.001)$. The mean MG-ADL score in the group of patients was 6.2 for MG patients with generalized weakness and 4.8 for patients with ocular weakness [5].

Fatigue is influenced by internal and external conditions. Internal conditions are physical and cognitive conditions; while external conditions can be mood disorders, anxiety, sleep disorders, musculoskeletal pain, treatment effects, especially analgesia, and weight gain as a side effect of steroid treatment. External conditions experienced by patients can cause secondary fatigue. Both primary and secondary fatigue can affect the patient's ability to perform daily activities, interact with family, and limit their work or social activities [7]. 
Based on the findings from previous studies above, this study aimed to determine whether there is a relationship between the level of fatigue and the ability to perform daily activities and to determine the factors that affect the level of fatigue in patients with MG.

\section{Materials and Methods}

In this cross-sectional study, samples were recruited by a consecutive sampling method from the Neurology Outpatient Clinic of Dr. Soetomo Hospital Surabaya, from April to June 2021. The inclusion criteria are age between 18 and 60 years, diagnosed with MG, cooperative, agreeing to participate, and willing to sign a consent form. The exclusion criteria are history of severe psychological disturbance, use of anti-depressant medication, history of other neurologic diseases, history of musculoskeletal diseases, and suffering from infectious diseases.

Subjects that met the criteria were then included in the study and underwent interviews and physical examinations. The severity of MG was assessed using MG Composite (MGC) Scale which was developed by Burns et al. by selecting items from Quantitave MG (QMG), Manual Muscle Test, and MG-ADL and by considering quality of life, disease severity risk, prognosis, validity, and reliability [10], [11]. The items in the MGC were assessed using 4 levels of severity (normal/no symptoms to severe symptoms), with the weighted scores for each item totaled, ranging from 0 (no symptoms) to 50 (maximum severity) [10], [11].

Fatigue is assessed using fatigue severity scale (FSS) which was developed by Krupp et al. to assess fatigue in patients with various neurological disorders [12]. The questionnaire consists of nine statements that represent the patient's level of fatigue [12], [13]. The assessment was conducted to see the effect of fatigue on motivation, activity, physical function, carrying out tasks, disruption to work, family, and social life [12], [13]. The scale used is a Likert scale with a scale of 1 (strongly disagree) to 7 (strongly agree), the results indicates that the higher the score, the higher the severity of the fatigue [12], [13]. Based on the FSS, the samples are classified into nonfatigue (FSS <4), borderline $(4<\mathrm{FSS}<5)$, and fatigue (FSS >5) [12], [13].

The ability to perform daily activities were assessed using MG-ADL scale which was developed by Wolfe et al. to assess the symptom status and daily activities of patients with MG [14]. There are eight questionnaire items filled out based on patient reports including ocular (2 items), oropharyngeal (3 items), respiratory (1 item), and extremity (2 items) domains [14], [15], [16].
The data were analyzed using SPSS 26.0 version. Demographic data were presented as mean $\pm S D$, minimum, maximum, and percentage. Rank-Spearman test was used to assess the correlation between fatigue and patient's ability to perform daily activities. Kruskal-Wallis test was used to assess the difference in performing daily activities between subgroups of fatigue. Multivariate linear regression analysis was used to assess the internal factors (age, type of MG, gender, severity of disease as measured by the MGC score, and presence of non-autoimmune comorbidities) and external factors (doses, duration of medications, and income) that influence fatigue. $p<0.05$ is considered significant. This study was approved by the ethical committee of Dr. Soetomo General Hospital.

\section{Results}

Thirty-one eligible samples (nine males and 22 females) were recruited in this study. The majority of the subjects $(71 \%)$ were women, with a mean age of $45.23( \pm 9.79)$ years and an onset age of 39.61 ( \pm 20.27 ) years. All study subjects have generalized MG type. The majority of subjects had no comorbidities $(64.5 \%)$, while others had hypertension (32.3\%) and rheumatic heart disease (RHD) (3.2\%). Five patients $(16.1 \%)$ had been diagnosed with thymoma by Thorax computed tomography (CT)-scan and had undergone thymectomy, while 26 patients had no history and clinical signs of thymoma based on anamnesis and physical examination (Tables 1 and 2 ). The mean income of the participants is 3.63 million IDR/month.

Rank-Spearman test showed a significant correlation between fatigue and the patient's ability to perform daily activities ( $p=0.005 ; p=0.488$ ) with $\mathrm{Cl}$ $95 \%$. The results of the FSS score analysis showed that the average score was $4.06 \pm 1.88$ with varying degrees of fatigue. Kruskal-Wallis test showed significant difference between MG-ADL score and subgroups of fatigue in $M G$ patients $(p=0.036)$. Multivariate linear regression analysis showed no significant correlation between fatigue, age, type of MG, sex, severity of disease, doses and duration of medications, and presence of non-autoimmune comorbidities $(F=1.093$, $\mathrm{p}=0.416$ ), with an $\mathrm{R}^{2}=0.388$ (Table 3 ).

\section{Discussion}

Most of the subjects included in this study were women, with a mean age of 45 years old, and all of the subjects had general MG type. A comparison 
of early and late onset MG in previous studies showed that MG predominates in young adult women and older men [17], [18]. This is supported by a cohort study which showed that cases of MG in women were higher in the first 5 decades of age, while MG in men occurred more in the $6^{\text {th }}$ decade of age [19]. Fan et al. explained that the early symptoms of MG usually manifest as an ocular type with characteristic weakness of the extraocular muscles and ocular misalignment [17], [20]. Nearly $90 \%$ of patients with ocular MG will develop into general MG within 3 years of onset [17], [20].

Table 1: Demographic profile

\begin{tabular}{lll}
\hline Variable & $\mathrm{n}(31)$ & $(\%)$ \\
\hline Sex & & \\
$\quad$ Male & 9 & 29 \\
$\quad$ Female & 22 & 71 \\
Type of MG & & \\
$\quad$ General & 31 & 100 \\
$\quad$ Ocular & 0 & 0 \\
History of thymoma from anamnesis and physical examination & & \\
$\quad$ Yes & 5 & 16.1 \\
$\quad$ No & 26 & 83.9 \\
Comorbidity & & \\
$\quad$ Hypertension & 10 & 32.3 \\
$\quad$ Rheumatic heart disease & 1 & 3.2 \\
$\quad$ None & 20 & 64.5 \\
\hline
\end{tabular}

The majority of subjects in this study had no comorbidities. Only one-third of the subjects had hypertension. Somers et al. stated that patients with autoimmune diseases such as MG will tend to develop secondary autoimmune diseases [21]. A previous study found that comorbid diseases in MG patients were more common in crisis conditions or on visits to the Emergency Unit, with the most comorbidities/> being dyslipidemia (60\%), type 2 diabetes (20\%), dysthyroidism (19\%), hypertension $(16 \%)$, and other autoimmune diseases (7\%) [22]. The mean income of participants in this study is 3.63 million IDR/month which is lower than regional minimal income (4 million IDR/month).

Table 2: Subject characteristics

\begin{tabular}{lll}
\hline Variable & Mean & SD \\
\hline FSS & 4.06 & 1.88 \\
MG-ADL & 3.00 & 3.51 \\
Age (year) & 45.23 & 9.79 \\
Age at onset (year) & 39.61 & 10.27 \\
MGC & 5.06 & 6.07 \\
Duration of medication (years) & 5.45 & 5.18 \\
Mestinon dose (tablet $60 \mathrm{mg}$ )/day & 3.87 & 1.28 \\
Methylprednisolone dose (tablet 4 mg)/day & 0.39 & 1.02 \\
Imuran dose (tablet 50 mg)/day & 0.03 & 0.18 \\
\hline FSS = Fatigue severity scale; MG-ADL = Myasthenia gravis-activities of daily living; MGC = Myasthenia \\
gravis composite scale.
\end{tabular}

The results of this study showed a significant correlation between fatigue and the ability to perform daily activities (Figure 1). Fatigue is a symptom found in various neuromuscular diseases that significantly affects the patient's quality of life, work status, and social and family life. Fatigue is also a major complaint in MG patients, even though the active symptoms of MG have been treated and the patient is in a stable condition with minimal manifestations [7], [23]. Fatigue in MG is physical and/or mental fatigue. Physical fatigue from a neurological perspective is muscle fatigue, while mental fatigue is a limitation to initiate activities that require self-motivation [4]. Physical and mental fatigue affects each other [5], [7], [9].
Table 3: Multivariate regression predictive analysis

\begin{tabular}{llllll}
\hline Model & Sum of Squares & df & Mean square & F & p-value \\
\hline Regression & 3356.317 & 11 & 305.120 & 1.093 & 0.416 \\
Residual & 5303.425 & 19 & 279.128 & & \\
Total & 8659.742 & 30 & & & \\
" "Simultaneous influence is present if $\mathrm{P}<0$. & & & &
\end{tabular}

The result of MG-ADL score analysis revealed that majority of the subjects was still able to perform daily activities independently. Only one person with a total score of 15 gave a score of 3 on the ability to chew and swallow (two oropharyngeal items), so the patient was already using a nasogastric tube at the time of the study. A positive correlation with moderate strength was found between the fatigue and the patient's ability to perform daily activities. This is in accordance with the previous systematic review who reported that higher fatigue scores in MG patients were associated with more severe disease severity as measured using the MGC, QMG, and MG-ADL scales [9], [24].

From the results of the hypothesis test of the multivariate linear regression model, it was found that age, gender, severity of the MGC scale, duration of treatment, MG medication dose, income, presence of thymoma, comorbid hypertension, and RHD did not affect the level of fatigue of patients with MG either simultaneously or partially. These results are not in accordance with the previous studies which explained that fatigue in MG patients was associated with severity, current patient age, gender, non-autoimmune comorbidities (DM type 2, non-allergic lung disease, hypertension, and cancer), dose and duration of treatment, and income each month [5], [9], [25]. This is probably because the fatigue rating scale used in this study was not specific for MG, so that the physical, cognitive, and psychosocial components assessed using the FSS scale were not relevant, as mentioned in the study of [7]. In addition, the limited number of subjects who participated in this study also caused discrepancies in the results of the analysis, because several factors had relatively homogeneous results, such as the age factor and the type of MG. Cultural and social factors in Indonesia are also need to be put into consideration because they influence perceptions of fatigue.

The presence of comorbidities, duration of treatment, dose of treatment, and income also did not affect the level of fatigue. This is probably because the choice of type of treatment for MG patients at the research hospital was adjusted to the Neurology Clinical Practice Guidelines which made acetylcholinesterase inhibitors (Mestinon) as the primary and first-line therapy. The administration of the acetylcholinesterase inhibitor drug is covered by health insurance so that it does not affect the patient's income. On the other hand, $\mathrm{Chu}$ et al. stated that the presence of these factors affected the fatigue, especially mental fatigue, because long-term use of glucocorticoids as first-line therapy options was not covered by health insurance [25].

Analysis of the coefficient of determination (R2) revealed that fatigue in MG patients is $38.8 \%$ can 


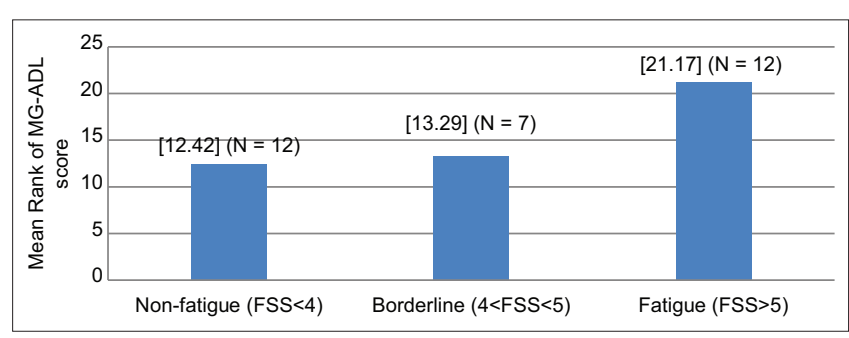

Figure 1: Mean rank of MG-ADL in subgroups of fatigue. FSS: Fatigue severity scale; MG-ADL: Myasthenia gravis-activity daily living

be explained by factors of present age, gender, severity of MGC, duration of treatment, dose MG medication, income, presence of thymoma, comorbid hypertension, and RHD. While, the remaining $61.2 \%$ is explained by other factors outside of this study. Several factors outside the study that may have an influence on fatigue, especially mental fatigue, include depression levels, anxiety levels, and sleep disturbances [5]. Meanwhile, factors outside the study that may have an influence on physical fatigue, as described in several previous studies are physical inactivity or a sedentary lifestyle, which will affect the patient's functional ability [6], [24].

Several limitations of this study include the absence of lifestyle and mental assessment, which may also affect the fatigue. The participants with no history and clinical sign of thymoma in this study did not undergo Thorax CT-scan which is required as a gold standard to diagnose thymoma, therefore the possibility of thymoma in these participants cannot be excluded and can influence fatigue. Furthermore, this study could not prove the effect of MG type on fatigue because the participants in this study did not undergo HLA and autoantibody tests to determine MG type.

\section{Conclusion}

Fatigue in patients with MG correlates with the ability to perform daily activities. There was a difference in performing daily activities between the subgroups of fatigue. However, the level of fatigue was not affected by age, gender, severity of the MG, duration of treatment, MG medication dose, income, presence of thymoma, comorbid hypertension, and comorbid RHD. Further research is needed to determine the factors that influence fatigue in MG.

\section{References}

1. Sieb JP. Myasthenia gravis: An update for the clinician. Clin Exp Immunol. 2014;175(3):408-18. https://doi.org/10.1111/cei.12217 PMid:24117026

2. Gilhus NE, Tzartos S, Evoli A, Palace J, Burns TM,
Verschuuren JJ. Myasthenia gravis. Nat Rev Dis Prim. 2019;5(1):30. https://doi.org/10.1038/s41572-019-0079-y PMid:31048702

3. Sadri Y, Haghi-Ashtiani B, Zamani B, Akhundi FH. Study of demographic, clinical, laboratory and electromyographic symptoms in Myasthenia Gravis patients referred to the neurology clinic of Rasoul Akram hospital in 2015. J Med Life. 2015;8(3):218-21.

PMid:28316694

4. Bhat S, Chokroverty S. Fatigue in neurologic disorders. Sleep Med Clin. 2013;8(2):191-212.

5. Hoffmann S, Ramm J, Grittner U, Kohler S, Siedler J, Meisel A. Fatigue in myasthenia gravis: Risk factors and impact on quality of life. Brain Behav. 2016;6(10):e00538. https://doi.org/10.1002/ brb3.538

PMid:27781147

6. Naumes J, Hafer-Macko C, Foidel S. Exercise and myasthenia gravis: A review of the literature to promote safety, engagement, and functioning. Int $\mathrm{J}$ Neurorehabilitation. 2016;3(218):2376

7. Farrugia ME, di Marco M, Kersel D, Carmichael C. A physical and psychological approach to managing fatigue in myasthenia gravis: A pilot study. J Neuromuscul Dis. 2018;5(3):373-85. https://doi.org/10.3233/JND-170299

PMid:29889078

8. National Health Services. Fatigue in Myasthenia Gravis United Kingdom: National Health Services; 2018.

9. Ruiter AM, Verschuuren JJ, Tannemaat MR. Fatigue in patients with myasthenia gravis. A systematic review of the literature. Neuromuscul Disord. 2020;30(8):631-9. https://doi. org/10.1016/j.nmd.2020.06.010

PMid:32718868

10. Burns TM, Conaway MR, Cutter GR, Sanders DB. Construction of an efficient evaluative instrument for myasthenia gravis: The MG composite. Muscle Nerve. 2008;38(6):1553-62. https://doi. org/10.1002/mus.21185

PMid: 19016543

11. Burns TM, Conaway M, Sanders DB. The MG composite: A valid and reliable outcome measure for myasthenia gravis. Neurology. 2010;74(18):1434-40. https://doi.org/10.1212/ WNL.0b013e3181dc1b1e PMid:20439845

12. Krupp LB, LaRocca NG, Muir-Nash J, Steinberg AD. The fatigue severity scale: Application to patients with multiple sclerosis and systemic lupus erythematosus. Arch Neurol. 1989;46(10):1121-3. https://doi.org/10.1001/archneur.1989.00520460115022 PMid:2803071

13. Butarbutar DT, Sudira PG, Astuti, Setyaningsih I. Uji reliabiltas dan validitas fatigue severity scale versi bahasa indonesia pada dokter residen RSUP Dr. Sardjito Yogyakarta. In: Pekan IImiah Regional XXVI Perhimpunan Dokter Spesialis Saraf Indonesia, Yogyakarta; 2014.

14. Wolfe GI, Herbelin L, Nations SP, Foster B, Bryan WW, Barohn RJ Myasthenia gravis activities of daily living profile. Neurology. 1999;52(7):1487-9. https://doi.org/10.1212/wnl.52.7.1487 PMid: 10227640

15. MuppidiS. Outcome measures in myastheniagravis: Incorporation into clinical practice. J Clin Neuromuscul Dis. 2017;18(3):135-46. https://doi.org/10.1097/CND.0000000000000156 PMid:28221304

16. Muppidi S, Wolfe GI, Conaway M, Burns TM, Group Mgcandms. MG-ADL: stiLI a relevant outcome measure. Muscle Nerve. 2011;44(5):727-31. https://doi.org/10.1002/mus.22140 PMid:22006686 
17. Fan L, Ma S, Yang Y, Yan Z, Li J, Li Z. Clinical differences of early and late-onset myasthenia gravis in 985 patients. Neurol Res. 2019;41(1):45-51. https://doi.org/10.1080/01616412.2018. 1525121

\section{PMid:30311866}

18. Melzer N, Ruck T, Fuhr P, Gold R, Hohlfeld R, Marx A, et al. Clinical features, pathogenesis, and treatment of myasthenia gravis: A supplement to the Guidelines of the German Neurological Society. J Neurol. 2016;263(8):1473-94. https:// doi.org/10.1007/s00415-016-8045-z

PMid:26886206

19. Alshekhlee A, Miles JD, Katirji B, Preston DC, Kaminski HJ. Incidenceand mortality rates of myasthenia gravis and myasthenic crisis in US hospitals. Neurology. 2009;72(18):1548-54. https:// doi.org/10.1212/WNL.0b013e3181a41211

PMid:19414721

20. Berrih-Aknin S, Le Panse R. Myasthenia gravis:Acomprehensive review of immune dysregulation and etiological mechanisms. J Autoimmun. 2014;52:90-100. https://doi.org/10.1016/j. jaut.2013.12.011 PMid:24389034

21. Somers EC, Thomas SL, Smeeth L, Hall AJ. Are individuals with an autoimmune disease at higher risk of a second autoimmune disorder? Am J Epidemiol. 2009;169(6):749-55. https://doi. org/10.1093/aje/kwn408

PMid:19224981

22. Diaz BC, Flores-Gavilán P, García-Ramos G, LorenzanaMendoza NA. Myasthenia gravis and its comorbidities. J Neurol Neurophysiol. 2015;6(5):1-5.

23. Feasson L, Camdessanché JP, El Mhandi L, Calmels $P$, Millet GY. Fatigue and neuromuscular diseases. In: Annales de Réadaptation et de Médecine Physique. Amsterdam, Netherlands: Elsevier; 2006. p. 375-84.

24. Westerberg E, Molin CJ, Lindblad I, Emtner M, Punga AR. Physical exercise in myasthenia gravis is safe and improves neuromuscular parameters and physical performance-based measures: A pilot study. Muscle Nerve. 2017;56(2):207-14. https://doi.org/10.1002/mus.25493

PMid:27935072

25. Chu HT, Tseng CC, Liang CS, Yeh TC, Hu LY, Yang AC, et al. Risk of depressive disorders following myasthenia gravis: A nationwide population-based retrospective cohort study. Front psychiatry. 2019;10:481. https://doi.org/10.3389/ fpsyt.2019.00481

PMid:31354544 